\title{
Anxiety Related To Chronic Cervical Spodylosis: A Case Report
}

\author{
N.P Singh ${ }^{1} *$, Suneeta Koul ${ }^{2}$
}

\section{Keywords: Anxiety, Chronic Cervical Spodylosis}

Anxiety means the unpleasant emotions characterized by the term "worry", "apprehension", "dread" and "fear" that we all experience at times in varying degrees (1). Anxiety is the complex blend of unpleasant emotions and cognitions that is both more oriented to the future and much more diffuse than fear (2).Anxiety has not only cognitive components but also physiological and behavioural components. At the cognitive level anxiety involves negative mood worry about the possible future, threat or danger, self-preoccupation and future threat and to control it if it occurs. At the physiological level anxiety often creates a state of tension and chronic over arousal which may affect readiness for delaying with danger. At behavioural level anxiety may create a strong tendency to avoid situations where danger might encounter but there is not the immediate urge to flee with anxiety as there is with fear (3). An increased risk of muscular skeletal disorder was found in workers with pre-existing anxiety and depression compared to the without them (4).

\section{CERVICAL SPONDYLOSIS}

Cervical spondylosis or degeneration problem of cervical spine generally occur in the middle or late years of life. Cervical degeneration can be manifested as axial pain, Radiculopathy or Myelopathy. The process can be acute as seen with disc hernia ion. The clinical picture may be more indolent from chronic cervical disc degeneration and may be confused (5). The patient affected with degenerative Arthritis or cervical spine can often although not necessarily present with common complaint of dizziness (6).Cervical spondylotic myelopathy has also been shown to cause increased anxiety and depression among patients as a result of their reduced mobility. (22)

\section{CASE REPORT}

In the present case study we examined the middle aged female patient who was suffering with chronic cervical spondylosis from last three years. In this case we observed that the patient has developed the anxiety due to this chronic illness so in order to measure the anxiety level of the patient we used the state and trait anxiety scale. This scale consists of 60 items out of which 30 are of trait and 30 are of state anxiety. There are no right and wrong responses in this scale.

\footnotetext{
${ }^{1}$ Reader, Jammu College of Physiotherapy

${ }^{2}$ Lecturer, Jammu College of Physiotherapy

*Responding Author

(C) 2016 I N Singh, S Koul; licensee IJIP. This is an Open Access Research distributed under the terms of the Creative Commons Attribution License (http://creativecommons.org/licenses/by/2.0), which permits unrestricted use, distribution, and reproduction in any Medium, provided the original work is properly cited.
} 


\section{Anxiety Related To Chronic Cervical Spodylosis: A Case Report}

Methodology involves giving proper instructions to the patient regarding this particular scale. After that the patient was asked to mark the responses and at last scoring process was done and on the basis of these scores we found that the patient scores high for both trait and state anxiety that means the patient is suffering from anxiety due to this chronic illness.

\section{DISCUSSION}

\section{Physiological Base Of Anxiety:-}

In the central nervous system the major mediators of the symptoms of anxiety disorder appear to be nor epinephrine, serotonin, dopamine, and Gama amino butyric acid (GABA). Other neurotransmitters and peptides, such as corticotrophin releasing factor may be involved. Peripherally the autonomic nervous system especially the sympathetic nervous system, mediates many of the symptoms. Positron emission tomography scanning has demonstrated increased flow in right Para hippocampal region and reduced serotonin type 1A receptor binding in the anterior and posterior cingulated and raphe of patient with panic disorder. MRI has demonstrated smaller temporal lobe volume despite normal hippocampal volume in these patients. The CSF studies in humans shows elevated level of ore in also known as hypo cretin, which is thought to play and important role in the pathogenesis of panic in rat models.(7) The chronic state of apprehension is often punctuated by acute anxiety attacks that may occur as often as several times a day or as frequently as once a month. During acute attacks the individual has an overwhelming feeling that something dreadful is about happen. This feeling is usually accompanied by such physiological symptoms as heart palpitations, rapid breathing, perspiration, muscle tension, faintness, and nausea. These physiological symptoms result from excitation of the sympathetic division of the autonomic nervous system. (8)

\section{Psychological Base Of Anxiety:-}

The individual suffering from anxiety also shows poor coping skills for example rigidity, inflexible problem solving ability, denial, avoidance, and impulsivity, extreme self-expectation, affective instability and inability to focus on problems etc. are associated with anxiety. Anxiety is also linked and perpetuated by the persons own pessimistic outcome expectancy and how they cope with feedback negativity. (9) Temperament and attitude have been found to be risk factors for anxiety. $(10,11)$ Anxiety results with tension and helplessness. If a realistic situation cannot be achieved the individual either remain in a state of severe anxiety or resorts to one or more of the defence mechanism in an attempt to reduce anxiety. Anxiety is assured to be as the core of all neuroses. Sometimes anxiety is very evident, the person appears strained and tense. Insomnia, indigestion, diarrhea

, inability to concentrate, depression, unhappy, guilty, rigid, no clear idea of why he is frightened, specific fears, worries constantly, sudden stress etc. are the psychological result of anxiety. (12) 


\section{Anxiety Related To Chronic Cervical Spodylosis: A Case Report}

\section{Physiological Base Of Cervical Sopndylosis:-}

Intervertebral disks lose hydration and elasticity with age and these loses lead to cracks and fissures. The surroundings ligaments also lose their elastic properties and develop traction spurs. The disc subsequently collapse as a result of biomechanical incompetence, causing the annulus to bulge outward. As the disk space narrows the annulus bulges and the facets override. This change in turn, increases motion at those spinal segments and further hastens the damage to the disk. Annulus fissures and herniation may occur. Acute disk hernia ion may complicate chronic spondylosis changes. As the annulus bulges, the cross-sectional area of the canal is narrowed; this effect may be accentuated by hypertrophy of the facet joints and of the ligament flavum, which becomes thick with age. Neck extension causes the ligaments to fold inward, reducing the interoposterior diameter of the spinal canal.

As disk degeneration occurs, the unicinate process overrides and hypertrophies, compromising the ventrolateral portion of the foramen. These changes contribute to the cervical spondylosis. Marginal osteophytes begin to develop. Additional stresses, such as trauma or long-term heavy use may exacerbate this process. These osteophytes stabilize the vertebral bodies adjacent to the level of the degenerating disk and increase the weight beating surfaces of the vertebral endplates. The result is decreased effective force on each of these structures. (13)

Cervical spondylosis is also involved in causing cervicogenic dizziness and imbalance with strong connections between the cervical receptors and balance function. It is understandable that the injury or pathology of neck may be associated with sense if dizziness or disequilibrium. (14)Accordingly the absent input from cervical proper receptors is considered to be related to muscle spasm in sternocelidomastoid and appear trapezius muscle. $(14,15,16)$

\section{Psychological Aspects:-}

Cervical spondylosis is also associated with various psychological factors because the mind is not created independently of the body but it is very definitely linked with it. When feelings and thoughts are not expressed by words or actions they find expression through some organ or organ system. Thus headache beginning in the back of the head, referred through neck and sometimes extending down to the back or into shoulders often represents tension expressed in neuromuscular system. (17) Anxiety that can make its effects in any part of the body may manifest as headache and pain in neck. Thus simulating cervical spondylosis.

So psychological evaluation of every cervical spondylosis patient should be done by a psychiatrist to determine any psychological disturbances. Understandable and appropriate treatment of such disturbances coupled with the conventional physical methods of treatment in cervical spondylosis can alleviate the symptoms and even cure the most resistant cases. (18)

The patient suffering from the vertigo also suffers from emotional tension and anxiety. Often other symptoms of neurons e.g. palpitation, breathlessness, fatigue, insomnia, profuse sweating 


\section{Anxiety Related To Chronic Cervical Spodylosis: A Case Report}

and tremors form of floating or swimming sensation or light headedness. (19)Emotive responses like anger, anxiety and fear motivate response to pain and contribute to complexities of painful experiences(20)Substantial amount of research has explored the possible relation between depressive disorders and chronic pain(21)More than one third of patients with chronic spondylotic myelopathy have a depressed and anxious mood .In these patients depression and anxiety scores are strongly related to decreased mobility, inconsistently associated with arm dysfunction and not associated with sensory deficit or sphincter dysfunction, suggesting that ambulatory dysfunction may cause symptoms of depression and anxiety among patients with chronic spondylotic myelopathy which is in support of our case study(22)Cervicogenic dizziness is accompanied by psychological symptoms such as anxiety and disturbances in con concentration and memory.(23)

\section{CONCLUSION}

The present case report is a rare study on psychological aspects related with cervical spondylosis, as not much of a work is available with respect to the anxiety and other psychological problems among patients with cervical spondylosis. The present area of study is required to be further researched upon in order to understand the proper relation between cervical spondylosis and psychological disturbances arising out of it. Further it is also important for the clinician that isorthopaedic surgeon, neuro surgeon, physiotherapist, osteopath and chiropractor to have proper understanding of the psychological connection of the patient with cervical spondylosis. So that beside the treatment of the clinical problem they also require a good psychological counselling or psychotherapy whichever is required as per the chronicity of the case, so as to overcome the anxiety and other psychological symptoms in patients with cervical spondylosis.

\section{REFERENCES}

1. Introduction to psychology,Ernest.R.Hilgard,Richard.C.Atikson\&Rita.L.Atikson, $6^{\text {th }}$ edition. Chapter No. 15,P.No 440.

2. Abnormal psychology, Robert. C. Carson. etal., Thirteen edition, chapter No. 6, P.No. 181,182 .

3. Abnormal psychology, Robert. C. Carson.etal.Thirteen edition, chapter No. 6, P.No. 185.

4. M. T. Dellcampoetal., Anxiety and depression predict muscular skeletal disorder health care disorders in workers, Archives of environmental and occupational health, Feb. 2016,DOI:10.1080/19338244.2016.

5. Strant. L. Weinstein, Joseph. A. Buck, Walter, Tureks Auwthopedics, Principles and their application; $6^{\text {th }}$ addition :Lippincott Williams and wilking Lippincott.

6. Sammuel. L. Turek, oethopedic, peinciples and their applications; $4^{\text {th }}$ addition, Vol.II Lippincott. Raven 2002,P.No.863.

7. Diseases of Ear, Nose and Throat, PL. Dingra, 4th edition: chapter No.7,p.No. 47.

8. William R.yates, Anxiety disorders, Background path physiology, emedicine, Medscape.com/article/2862, Nov.3,2015. 


\section{Anxiety Related To Chronic Cervical Spodylosis: A Case Report}

9. Introduction to psychology,Ernest.R.Hilgard,Richard.C.Atikson\&Rita.L.Atikson,6th edition. Chapter No. 16,P.No 458.

10. GU, Ruoleio; Huang, Yu-Jia (2010), “Anxiety and Feedback negativity”. Psychophysiology.doi:10.1111/-J 1469-8986.2010.00997.X.

11. American Psychatric Association (2013).Diagnostic and statistical manual of mental disorders, Fifth edition, Arlington, VA: American Psychatric Association.

12. Bienvenus, O. Joseph; Ginsburg. Golda, S (2007). Prevension of anxiety disorders., International Review of $\quad$ Psychiatry $19 \quad$ (6):64754;doi:10.1080/09540260701797837.PMID 18092242

13. Introduction to psychology,Ernest.R.Hilgard,Richard.C.Atikson\&Rita.L.Atikson,6th edition. Chapter No. 16,P.No 457-459.I

14. Hasan Ahmad Hasan, cervical spondylosis ,Background path physiology, Emedicine. MedScap, com. article 3060, oct.22,2014.

15. Brown.jj. cervical contribution to balance cervical vertigo. In;Berth A, Vidal PP,craf Graf w.eds.the head and neck sensory motor system New York. NY: Oxford university Press 1992:644-647.

16. Dejong.PTVM.etal., Atxia and nystagmus induced by injection of local Anestetic in neck. Ann-neurol 1977:1:242-246.

17. Ryan M.S, Cope.S.Servical vertigo.;Lencet.1955:2:1355-1358.

18. Edward, $\mathrm{W}$ and O.Spurgeon, E, Psychosomatic medicine a clinical study of psychological reactions, 3rd addition W.B.Sounders Company,1958.

19. Wilkinson, M., Symptomatology, cervical Spondylosis, second edition,59-67,William Heinemann, London 1971.

20. Gifford, L S. Butler,DS.The integration of pain sciences into clinical practice. Journal of Hand Therapy 1997; 10:86-95.

21. Gupta, MA.Is chronic pain a variant of depressive illness, a critical review. Canadian Journal of Psychiatry 31:241-248, 1986[Pub Med].

22. Stoffman MR ,Roberts MS, King JT Jr, Cervical Spondylotic myelopathy, depression and anxiety: a cohort analysis of 89 patients.Neurosurgery.2005.Aug;57(2):307-13.[Pub Med].

23. Malstron EM et. al, Cervicogenic dizziness-musculosekelatal findings before and after treatment and long term out come. Disabil Rehabil.2007;29(15):11931205.doi:10.1080/09638280600948383. [Pub Med].

How to cite this article: N Singh, S Koul (2016), Anxiety Related To Chronic Cervical Spodylosis: A Case Report, International Journal of Indian Psychology, Volume 3, Issue 3, No. 7, DIP: 18.01.116/20160303, ISBN: 978-1-365-12175-3 